\title{
Feasibility Study of Community Earthquake Warning System Proposed for Mbeya City and Surrounding Regions
}

\author{
Asinta Manyele, Alfred Mwambela \\ Department of Electronics and Telecommunications, University of Dar es Salaam, Dar es Salaam, Tanzania \\ Email: asinta3@yahoo.com
}

Received 18 June 2014; revised 20 July 2014; accepted 27 August 2014

Copyright (C) 2014 by authors and Scientific Research Publishing Inc.

This work is licensed under the Creative Commons Attribution International License (CC BY).

http://creativecommons.org/licenses/by/4.0/

(c) (i) Open Access

\begin{abstract}
The Mbeya city and its surrounding regions (Rukwa, Katavi and Njombe) in south western Tanzania, fall among the fast growing economical regions in Tanzania. It is also unfortunately under potential for seismic risk due to its proximity to the western and eastern junction of the East African Rift (EAR) Valley. Construction of Community Earthquake Early Warning (CEEW) system model based on community owned MEMS accelerometer sensors in being proposed for the region. To optimize the warning time function and as the process of planning and designing the community-hosted seismic network, the paper presents the simulation of warning times that can be realized in this region based on the distribution of sensor stations in relation to the historical strong earthquakes and target sites. The distribution of sensor stations determines the detection and reporting time of the event, while location of earthquakes and position of target site determine the available warning time for the target to be protected. Testing the various sensor station configurations (regional, On-site and Hybrid) models of CEEWS by simulation of scenario earthquakes, the hybrid configuration that distributes sensor stations closer to the source and on target sites, was able to provide at least 5 seconds of warning times to various targets. This time has been demonstrated to be enough for shutting down hazardous industrial processes and for people to take cover at safer locations to reduce injuries.
\end{abstract}

\section{Keywords}

Community-Hosted Sensors, Sensor Station Configuration, Warning Times, Target Sites

\section{Introduction}

In the past few years, research and development of earthquake early warning (EEW) have shown significant potential for the mitigation of earthquake disasters [1]-[4]. Countries/areas such as US, Japan, Mexico, and Taiwan 
have established practical EEW function that protect sensitive structures and provide warning of few seconds to tens of seconds when strong earthquakes are detected [1]-[4].

Two types of EEW systems (regional and on-site) are mostly in operation around the world and in both systems, warning time is a critical factor to consider as all the public would like to be informed ahead of strong earthquake to save lives. The distribution of sensor network when combined with the reliable communication infrastructure and data processing speed of EEW systems sets the limit to the warning times that can be available to monitor targets before the strong ground motion arrives.

The CEEW system in this study is based on the community sensor deployment and is limited to cities or urban areas where power and internet connectivity is currently possible in the south-western Tanzania (SWTZ) zone. To guarantee some earthquake warning times for the target sites, distribution of sensor stations relative to the locations of historical strong earthquakes in the region, is being evaluated through simulation. That is, varying the positions of sensor stations across SWTZ region, the resulting warning time at each target site as well as the expected level of ground shaking is explored for establishment of CEEWS in SWTZ region.

\section{General Seismicity of the SWTZ Region and Location of Target Sites}

\subsection{Seismicity of SWTZ Region}

The SWTZ region is seismically active due to its proximity to the western and eastern junction of the East African Rift (EAR) Valley [5]-[8]. This fact is demonstrated by the occurrences of several earthquakes with varying magnitudes as detailed in Figure 1 that maps the earthquake recorded in the region between 1973 and May 2012.

From Figure 1, the events that have been recorded in Tanzania for the period of 1973 to May 2012, using the United States Geological Survey (USGS) catalogue, are concentrated along the Lake Tanganyika, Lake Nyasa and in the North-Eastern zones, which is the location for the East African Rift (EAR) Valley system across Tanzania [1].

\subsection{Selected Target Sites}

The South-Western Tanzania (SWTZ) extends from Njombe, including Mbeya city, Tunduma, Sumbawanga, Namanyere, Mpanda, and Kigoma townships. This region is part of seismically active region, the Western Rift Valley of Africa (WRA), a branch of East African Rift Valley system (EARS) where most recent strong earthquakes with some observable impacts to the communities have been observed [6]-[11]. The proposed CEEWS in this region aims at providing seismic protection to several urban settlements or population centers from earthquakes that may originate from the Lake Tanganyika and Lake Nyasa seismic sources. The Sumbawanga Township and Mbeya city are selected as major target sites in this study, and the other target sites considered for warning issuance whenever possible are Kyela, Njombe, Tunduma, Namanyere, Mpanda and Kigoma Townships.

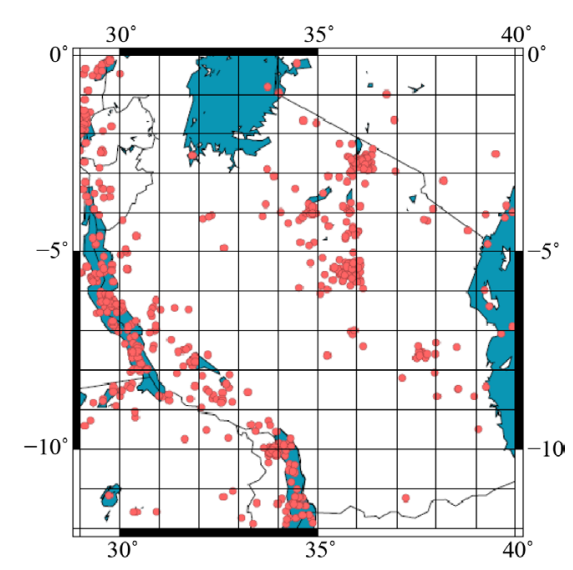

Figure 1. Event recorded between 1973 and May 2012 in Tanzania. 


\subsection{Scenario Earthquakes Selected for Simulation}

The scenario earthquakes considered in this study for warning time simulation includes: magnitude 6.5 earthquake of October 2000; magnitude 6.8 earthquake of December 5, 2005, both from Lake Tanganyika, magnitude 6.0 of February 19, 2009, and magnitude 5.9 earthquake of December 20, 2009 along Lake Nyasa seismic source [1] [6] [9]-[11]. The Sumbawanga Township is at a distance of about $100 \mathrm{~km}$ from the nearest Lake Tanganyika 6.5 earthquake epicenter, while Mbeya city is situated at a distance of about $164 \mathrm{~km}$ from the Lake Nyasa earthquake epicenters. Other target points considered for warning issuance whenever possible are Kyela, Njombe, Tunduma, Namanyere, Mpanda and Kigoma townships. With respect to the magnitude 5.9 earthquake from Lake Nyasa, distances from the earthquake to Kyela, Njombe and Tunduma are 42 km, 155 km, and 138 $\mathrm{km}$, respectively. Considering the Lake Tanganyika earthquake epicenter (magnitude 6.5), Namanyere, Mpanda and Kigoma towns are at the distances of $67 \mathrm{~km}, 187 \mathrm{~km}$ and $364 \mathrm{~km}$, respectively. Table 1 shows the distances of all the target sites to the epicenters of the four scenario earthquakes used in the simulation.

Table 1. Target sites and their epicentral distances to the scenario earthquakes.

\begin{tabular}{|c|c|c|}
\hline Target Site & Magnitude of Scenario Earthquake & Distance, $\mathrm{R}$ \\
\hline \multirow{4}{*}{ Kyela } & 6.8 & 606.2 \\
\hline & 6.5 & 397.56 \\
\hline & 6.0 & 65.18 \\
\hline & 5.9 & 42 \\
\hline \multirow{4}{*}{ Njombe } & 6.8 & 651.28 \\
\hline & 6.5 & 467.42 \\
\hline & 6.0 & 176.55 \\
\hline & 5.9 & 155.63 \\
\hline \multirow{4}{*}{ Mbeya city } & 6.8 & 493.19 \\
\hline & 6.5 & 306.06 \\
\hline & 6.0 & 184.03 \\
\hline & 5.9 & 164.23 \\
\hline \multirow{4}{*}{ Sumbawanga } & 6.8 & 296.05 \\
\hline & 6.5 & 100.67 \\
\hline & 6.0 & 338.15 \\
\hline & 5.9 & 327.97 \\
\hline \multirow{4}{*}{ Tunduma } & 6.8 & 487.86 \\
\hline & 6.5 & 269.12 \\
\hline & 6.0 & 146.34 \\
\hline & 5.9 & 138.99 \\
\hline \multirow{4}{*}{ Mpanda } & 6.8 & 162.97 \\
\hline & 6.5 & 187.95 \\
\hline & 6.0 & 516.57 \\
\hline & 5.9 & 502.79 \\
\hline \multirow{4}{*}{ Kigoma } & 6.8 & 147.71 \\
\hline & 6.5 & 364.01 \\
\hline & 6.0 & 740.39 \\
\hline & 5.9 & 727.44 \\
\hline \multirow{4}{*}{ Namanyere } & 6.8 & 216.5 \\
\hline & 6.5 & 67.55 \\
\hline & 6.0 & 417.56 \\
\hline & 5.9 & 407 \\
\hline
\end{tabular}




\section{Sensor Station Configurations for Simulation}

The community-hosted seismic sensor stations are positioned into regional, onsite, and hybrid configurations (see Figure 2) each at a time during simulation process. The regional earthquake warning method, positions at least five seismic sensors next to the seismic source, to rapidly detect an earthquake onset and contribute station observation data to estimate the earthquake source parameters. The onsite method, embed at least five sensor stations directly on the major target sites (Sumbawanga town and Mbeya city), so that during the earthquake occurrences the beginning of P-wave ground motion observed at these target sites can be used to predict the ensuring ground motion of S-waves at the same sites. For hybrid method, about 49 seismic sensor stations are proposed, where some sensors are embedded on the target sites and some sensors are installed near the seismic sources. Like the other two configurations, five sensor station data would be required to estimate earthquake source parameters.

In Figure 2, yellow triangles are target sites and green triangles are sensor stations/arrays for recording earthquake ground motion across the region.

\section{Methodology}

To accomplish the objective of the research, examining the warning time that can be realized at target sites for various scenario earthquakes, while adopting different sensor station configurations (see Figure 2), an algorithm for simulating the earthquake travel times across the region was developed for the study. This algorithm utilizes the event location, station location, target site position and the seismic waves travel velocities across the region to estimate the warning times at the target sites. The algorithm also, uses empirical peak ground acceleration (PGA) attenuation relationship across the region to predict earthquake ground shaking levels to be expected at each target sites. The earthquake simulations were performed using the four sensor positioning (Figure 2) and the four selected scenario earthquakes to estimate the achievable warning time at each target site. The optimal

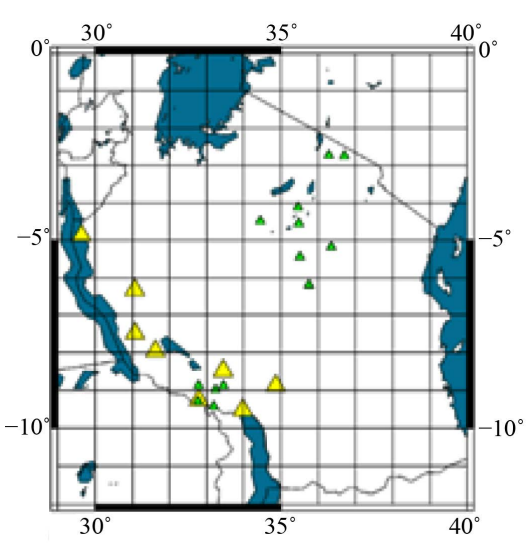

(a) TZNet

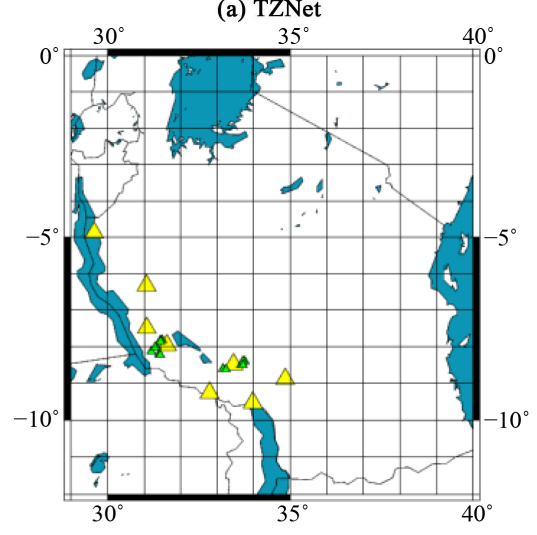

(c) Onsite

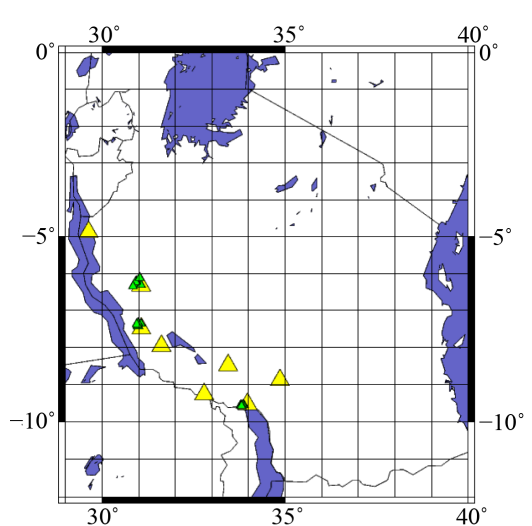

(b) Regional

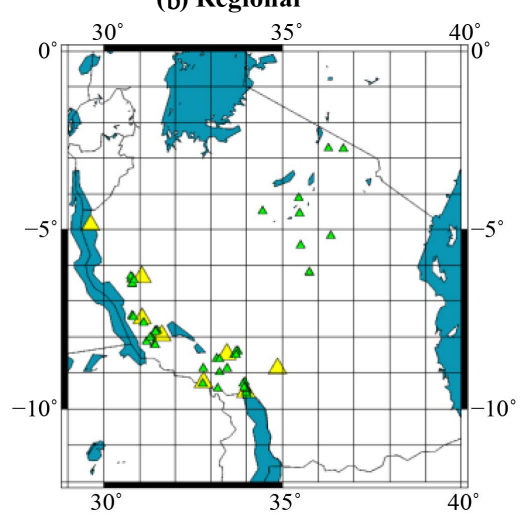

(d) Hybrid

Figure 2. Sensor configurations considered in simulation. 
sensor positioning was to be the one that provides at least five seconds to major target sites for all scenario earthquakes.

\subsection{Warning Time Estimation}

To estimate warning times, $P$ - and $S$-wave arrive times at different stations and target sites were measured for each simulation case. Assuming that the time needed for $P$-wave to reach sensor station and target site is $T_{p}$, the time needed to process data and estimate earthquake source parameter $T_{p r}$, the time for each sensor station to record sufficient $P$-wave data for earthquake parameter estimation process to be $T_{d}$, and that five stations must trigger to reduce false alarm with time for waiting for five triggers to be $\left(T_{T r}\right)$, Equations (1) is used to estimate time for reporting earthquake event.

$$
T_{r}=T_{P}+T_{p r}+T_{d}+T_{T r}
$$

That is, to calculate the warning time, times for $P$-wave triggers from the first five closest stations to the event, as well as the waiting time for triggers acquisition were added as data processing time. In this study the time for processing data $T_{p r}$ is assumes to be 10 seconds, while the time $T_{d}$ to record sufficient $P$-wave data at each site is assumed to be 4 seconds. The time $T_{p}$ depends on the distance from the event to recording point and the time $T_{T r}$ depends on the sensor station separation distances.

Then, warning time for each target site is estimated using Equation (2)

$$
T_{W}=T_{S}-T_{r}
$$

By simulating the four scenario earthquakes used in this study while alternating among the three proposed sensor network configurations, the measurements of seismic wave's arrival time and warning times at various target sites were measured for calculations of warning times.

\subsection{PGA Predictions}

Warnings are to be issued when the predicted PGA value at a station or target point exceeds the threshold value that is set at $0.001 \mathrm{~g}$ in this study. Thus, for each simulation case, the PGA values at each station and each target site were also predicted empirically using Equation (3).

$$
\text { PGA }=1.42 \exp (1.43 \mathrm{M}) \mathrm{R}^{-1.2}(0.719 \ln (\tau))
$$

where PGA is peak ground acceleration, $\mathrm{M}$ is earthquake estimated magnitude, $\mathrm{R}$ is the epicentral distance and $\tau$ is the $P$-wave observing time.

\section{Results and Discussion}

Each simulation process simulated an individual scenario event recorded in the SWTZ zone at a time through three steps that starts with significant detection of $P$-waves PGA at one station, estimation of distances between station and targets/other stations, predicting the expected $S$-waves PGA and arrival times at other stations in the network, and finally the checking of the alarm decision criteria (trigger for five stations and PGA levels) for CEEWS.

\subsection{Simulated Warning Times Results}

When all the scenario earthquakes were simulated with the proposed sensor positioning, available target warning times variations across the region were plotted as shown in Figure 3.

According to Figure 3, warning times for each sensor configuration increases with epicenter distances, but at varying rates. The Hybrid configuration show higher warning times at comparable epicentral distances, and the TZNet configuration shows the lowest warning times. The summary of the simulated warning times trends for the four sensor positioning and four scenario earthquakes are shown in Table 2 for the major target sites.

Using Table 2, only the hybrid sensor configuration guarantees the five warning times to the target sites for all four scenario earthquakes. That is, the hybrid configuration satisfies the criteria for the design of CEEWS in this region and is therefore considered as an optimal configuration of sensor stations. 


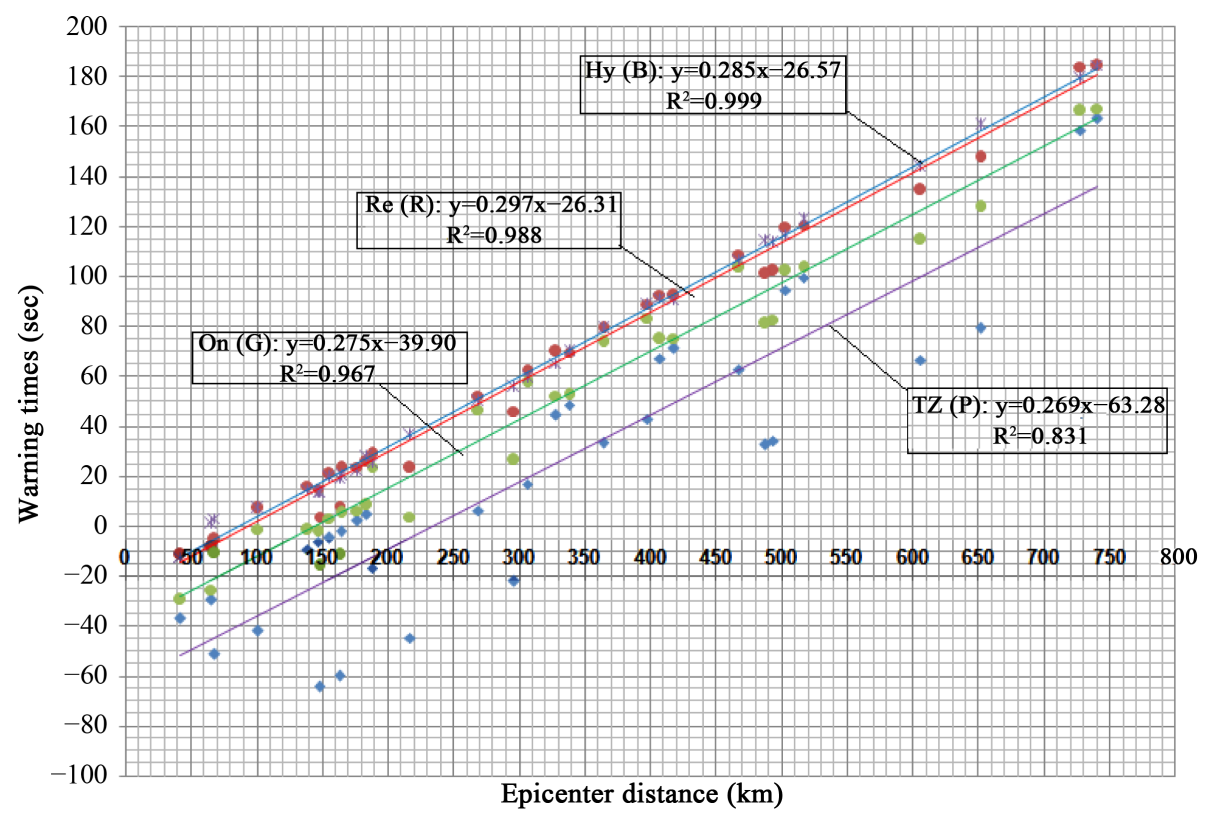

Figure 3. Available warning times at target sites for each sensor configuration.

Table 2. Simulated warning times for major target sites from four scenario earthquakes.

\begin{tabular}{cccccccccc}
\hline & \multicolumn{8}{c}{ Warning time for various sensor configurations (s) } \\
\cline { 2 - 10 } & \multicolumn{2}{c}{ TZNet } & \multicolumn{2}{c}{ Onsite } & \multicolumn{2}{c}{ Regional } & \multicolumn{2}{c}{ Hybrid } \\
\hline Scenario event magnitude & SBA & MBY & SBA & MBY & SBA & MBY & SBA & MBY \\
6.8 & 22 & 70 & 44 & 98 & 58 & 118 & 60 & 120 \\
6.5 & -35 & 20 & -15 & 45 & 3 & 75 & 5 & 80 \\
6.0 & 30 & -15 & 50 & 10 & 68 & 26 & 70 & 28 \\
5.9 & 25 & -20 & 50 & 6 & 68 & 20 & 70 & 22 \\
\hline
\end{tabular}

\subsection{PGA Variations across the Region}

There is correlation between PGA values to the experienced damages, but not always absolute agreement since experiences and damage can be affected by many other factors, including the quality of earthquake engineering, type soil cover, as well as construction practices. Generally, PGA values of $0.001 \mathrm{~g}$ to $0.01 \mathrm{~m} / \mathrm{s}^{2}$ are perceptible by people, $0.02 \mathrm{~g}$ to $0.2 \mathrm{~m} / \mathrm{s}^{2}$ people lose their balance, and above $0.50 \mathrm{~g}$ are very high and only well-designed buildings can survive if the duration is short. For simplicity, in this study PGA values above $0.5 \mathrm{~g}$ are considered to cause severe ground shaking, PGA values between $0.5 \mathrm{~g}$ and $0.2 \mathrm{~g}$ are considered to cause strong ground shaking, PGA values below $0.2 \mathrm{~g}$ but above 0.01 are classified to cause weak ground shaking, and PGA values below $0.01 \mathrm{~g}$ are considered unfelt. The simulate PGA variations across the SWTZ region from the four scenario earthquakes considered in this study, are presented in Figure 4.

From Figure 4, all PGA curves simulate the decrease in PGA values as the distance from the event epicenter increase. Largest earthquake (magnitude 6.8) show large values of PGA at each grid point and attain PGA values than can be felt at larger distances. The decrease in PGA with distance for each case is large close to the epicenter and decrease as distance increases.

Considering PGA curve for magnitude 6.8 earthquakes, severe ground shaking is predicted to reach a distance of $160 \mathrm{~km}$, strong shaking will be between $160 \mathrm{~km}$ and $360 \mathrm{~km}$, weak ground shaking is between $360 \mathrm{~km}$ and $700 \mathrm{~km}$, while the other areas will not feel the event.

Magnitude 6.5 earthquakes is simulated to cause severe ground shaking up to a distance of $110 \mathrm{~km}$, strong ground shaking between $110 \mathrm{~km}$ and $230 \mathrm{~km}$, weak ground shaking between $230 \mathrm{~km}$ and $480 \mathrm{~km}$, while areas above $480 \mathrm{~km}$ from the epicenter will not feel the event. 


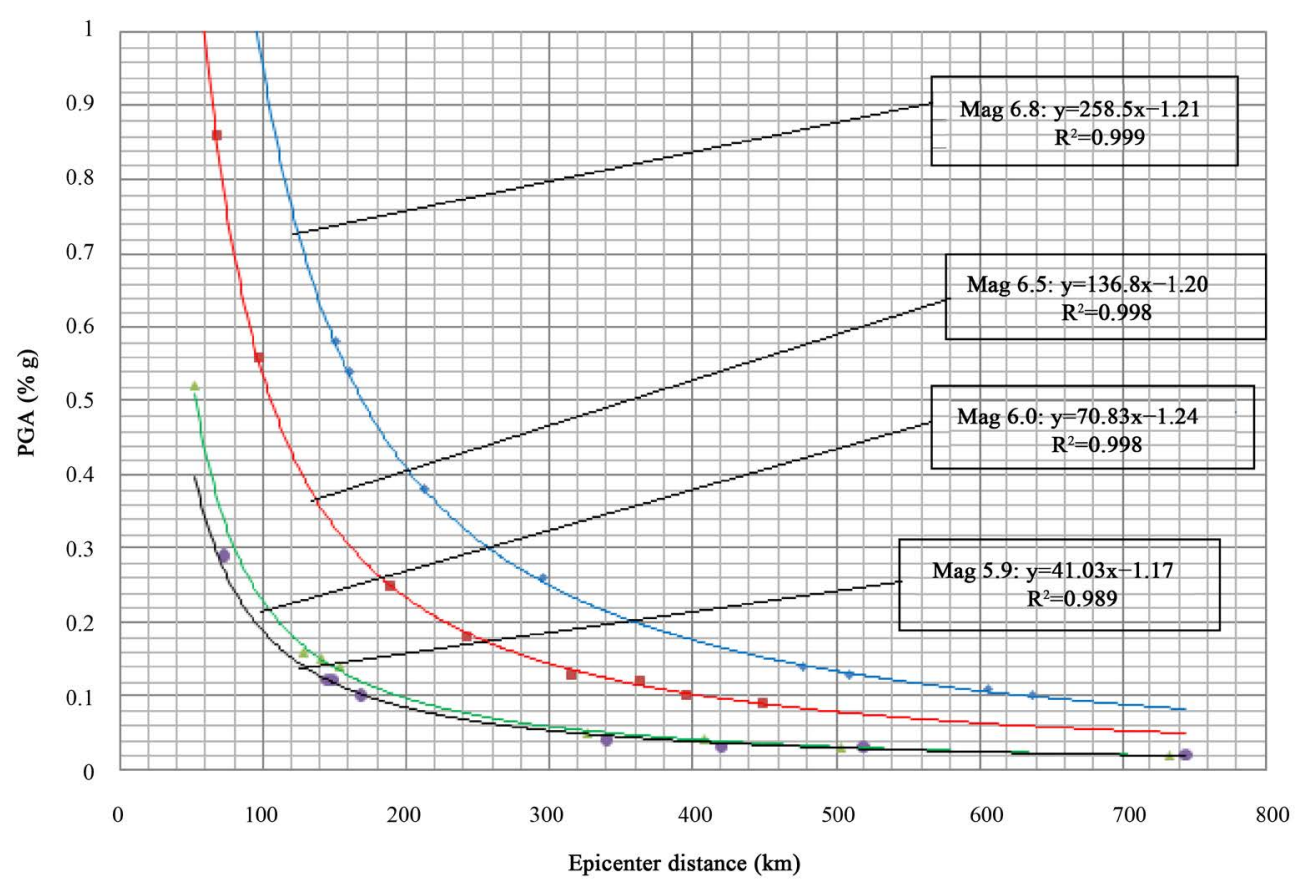

Figure 4. Predicted PGA values at each epicentral distance for various earthquake magnitudes.

Magnitude 6.0 is simulated with severe ground shaking that reaches $80 \mathrm{~km}$, strong ground shaking between $80 \mathrm{~km}$ and $110 \mathrm{~km}$, weak ground shaking between $110 \mathrm{~km}$ and $230 \mathrm{~km}$ and areas above $230 \mathrm{~km}$ will not feel the event.

Magnitude 5.9 is simulated to cause severe ground shaking that reaches about $43 \mathrm{~km}$, strong ground shaking between $43 \mathrm{~km}$ and $90 \mathrm{~km}$, weak ground shaking between $90 \mathrm{~km}$ and $200 \mathrm{~km}$, while above $200 \mathrm{~km}$ the event will not be felt.

Thus, when the Sumbawanga Townships is predicted to be in severe ground shaking from magnitude 6.5 earthquakes, people dwelling in this town will be warned with only five seconds to move to safe positions. When the same city is predicted to fall under strong ground shaking of magnitude 6.8 earthquakes, there will be 22 seconds of warning time before the start of strong ground shaking at their location. Due to its location, a minimum of $164 \mathrm{~km}$ from the considered earthquakes, Mbeya city is simulated with strong shaking from magnitude 6.8 with about 60 seconds of warning times.

\section{Conclusion}

EEW system can play an important role for earthquake hazard mitigation in Mbeya city and surrounding regions. The evaluation of warning capability in terms of warning time $T_{w}$ is essential for system design to reflect the “ideal” performance of an CEEW system. The hybrid sensor network configuration appears to offer reasonable warning time to mitigate seismic hazards and should be considered for implementation of CEEWS to improve seismological observations in the region and for an early-warning purpose.

\section{References}

[1] USGS Web Site 2000, 2005, 2009. www.earthquakes.usgs.gov/

[2] Böse, M., Ionescu, C. and Wenzel, F. (2007) Earthquake Early Warning for Bucharest, Romania: Novel and Revised Scaling Relations. Geophysical Research Letters, 34. http://dx.doi.org/10.1029/2007GL029396

[3] Horiuchi, S., Negishi, H., Abe, K., Kamimura, A. and Fujinawa, Y. (2005) An Automatic Processing System for Broadcasting System Earthquake Alarms. Bulletin of the Seismological Society of America, 95, 347-353.

[4] Hsiao, N.C., Wu, Y.M., Zhao, L., Chen, D.Y., Huang, W.T., Kuo, K.H., Shin, T.C. and Leu, P. L. (2011) A New Prototype System for Earthquake Early Warning in Taiwan. Soil Dynamics and Earthquake Engineering, 31, 201-208.

[5] Mavonga, T. (2007) An Estimate of the Attenuation Relationship for the Strong Ground Motion in the Kivu Province, Western Rift Valley of Africa. Physics of the Earth and Planetary Interiors, 162, 13-21. 
http://dx.doi.org/10.1016/j.pepi.2007.02.001

[6] Mavonga, T.G. and Durrheim, R.J. (2009) Probabilistic Seismic Hazard Assessment for Democratic Republic of Congo and Surrounding Areas, Western Rift Valley of Africa. Special Africa Array Issue of South African Journal of Geology, 112, 329-342.

[7] Espinoza-Aranda, H.M. and Rodriguez, F.H. (2003) The Seismic Alert System of Mexico City. In: Lee, W.H.K., Kanamori, H., Jennings, P.C. and Kisslinger, C., Eds., International Handbook of Earthquake and Engineering Seismology, Part B, Academic Press, Amsterdam, 1253-1259.

[8] Macheyeki, A.S., Delvaux, D., De Batist, M. and Mruma, A. (2008) Fault Kinematics and Tectonic Stress in the Seismically Active Manyara-Dodoma Rift Segment in Central Tanzania-Implications for the East African Rift. Journal of African Earth Sciences, 51, 163-188. http://dx.doi.org/10.1016/j.jafrearsci.2008.01.007

[9] UN Office for the Coordination of Humanitarian Affairs (2014) Tanzania-Earthquake OCHA Situation Report No. 1. Ref: OCHA/GVA-2000/0185. OCHA Situation Report No. 1 Tanzania-Earthquake 2 October 2000. http://reliefweb.int/report/united-republic-tanzania/tanzania-earthquake-ocha-situation-report-no-1

[10] UN Office for the Coordination of Humanitarian Affairs (2014) Ref: OCHA/GVA-2000/0193. OCHA Situation Report No. 2 Tanzania-Earthquake 5 October 2000. Tanzania-Earthquake OCHA Situation Report No. 2. http://reliefweb.int/report/united-republic-tanzania/tanzania-earthquake-ocha-situation-report-no-2

[11] UN Office for the Coordination of Humanitarian Affairs (OCHA) (2014) East Africa: Earthquake OCHA Situation Report No. 1. Ref: OCHA/GVA-2005/0217. 2005/12/05. OCHA SITUATION Report NO. 1. DRC, Tanzania, Burundi, Kenya, Rwanda, Uganda, Earthquake-Lake Tanganyika 5 December 1995.

http://reliefweb.int/report/democratic-republic-congo/east-africa-earthquake-ocha-situation-report-no-1 
Scientific Research Publishing (SCIRP) is one of the largest Open Access journal publishers. It is currently publishing more than 200 open access, online, peer-reviewed journals covering a wide range of academic disciplines. SCIRP serves the worldwide academic communities and contributes to the progress and application of science with its publication.

Other selected journals from SCIRP are listed as below. Submit your manuscript to us via either submit@scirp.org or Online Submission Portal.
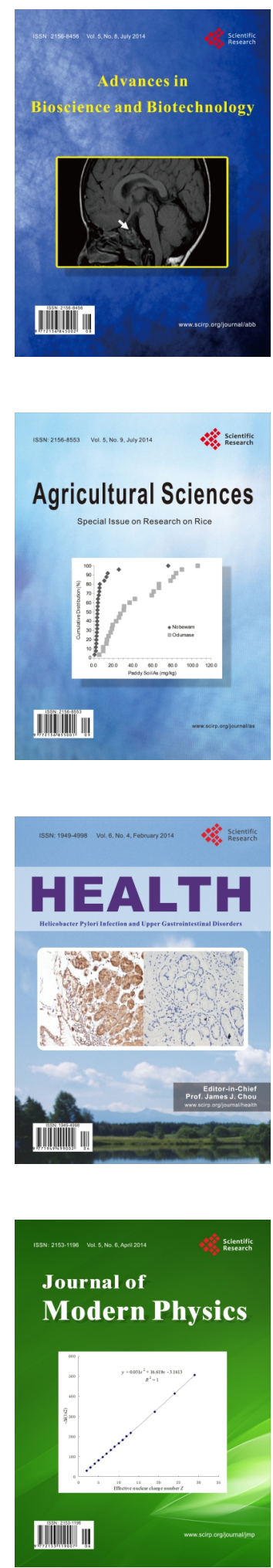
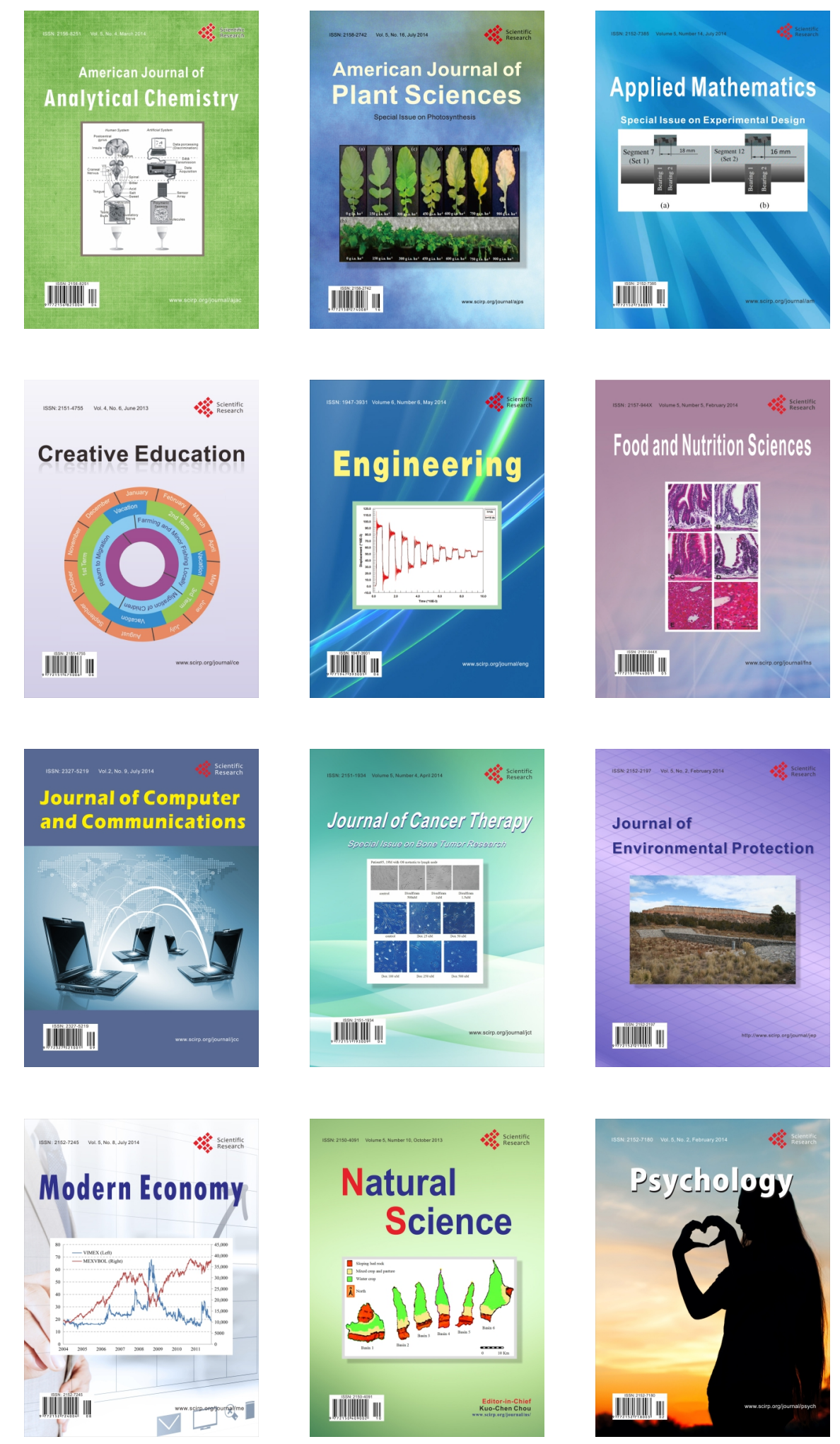